POLLACK PERIODICA

An International Journal for Engineering and Information Sciences

DOI: $10.1556 / 606.2016 .11 .1 .15$

Vol. 11, No. 1, pp. 163-174 (2016)

www.akademiai.com

\title{
ARCHITECTURE AND DESIGN, FLEXIBLE BUILDING CONSTRUCTION
}

\author{
Jan WERNER \\ PhD student at Faculty of Engineering and Information Technology, University of Pécs \\ Boszorkány u. 2, H-7624 Pécs, Hungary, \\ Lecturer at UAS FH JOANNEUM GmbH, Graz, Austria \\ Managing Director at WEST PLUS GmbH, the dynamic space company, Leoben, Austria \\ Managing Director at Arch-Vision, architectural design office, Graz, Austria \\ e-mail: j.werner@westplus.at
}

Received 22 July 2015; accepted 7 October 2015

\begin{abstract}
The society is changing faster and faster. The technical development times are constantly growing shorter, whereas the rate of development is increasing exponentially. Hence, the treatment of the environment is also changing. The society responds to these changes by becoming more and more flexible and adapts itself to new situations.

In contrast to this, the construction is static and the construction industry is conservative. The further development of construction methods and materials is also slow. For centuries, the same materials have been used.

The requirements to living space become more and more multiple. Dwellings are usually made for one use, one setting of requirements. The result is a growing vacancy of dwellings. The shown project, which is under realization at the moment is coming up with one possible solution for a dwelling to use it with multiple requirements.
\end{abstract}

Keywords: Pluralization of lifestyles, Society, Construction methods, Social change, Flexible dwellings

\section{Rising renting rates and diverging requirement of accommodation}

\subsection{The impact of urbanism on living costs}

Urban space offers a high quality of habitation. This is one of the main reasons that cities are growing. Because of the often limited growth potential in cities, the cost of land is rising sharply. These costs are usually added on the purchase or rental price of residential units. In Graz/Austria this development means that prices for purchase or renting apartments increased up to $20-25 \%$ over the past 5 years. By contrast to that the 
per capita income of the population increases barely. Forecasts from studies show a continuation of this trend up to 2050 [1].

The result is: Measured by the available monthly income of a person, the expenses for rent/purchase increases enormously. This cannot be financed by the user for a long time. A possible solution can be the reduction of the size of residential units and with this a reduction of the monthly cost of living. The result is: The size of apartments has to decrease again.

\subsection{The impact of social change on requirements of residential units}

A plurality of styles of living together in the society is detectable in a faster and faster changing society. Through the increasing plurality of styles of living together and the increasing speed of this pluralization, the requirements to an accommodation or to the space in residential units will change faster and stronger. People avoid space which lacks proper function. People have to avoid space, which is under modification or adaptation work. Studies prospect an ongoing trend in a growing plurality of lifestyles up to 2050 [2].

As a result, the structure of residential units has to respond to an ever-increasing variety of types of use and more varied demands of living. Otherwise, apartments can be used only for a very limited clientele with clearly designated requirements for defined residential units. This in turn means that an apartment is not suitable for the majority of home seekers.

\subsection{The gap}

The long-term trend of urbanization entails rising prices for real estates in urban regions. Habitation is getting more expensive. But because the average income of an employee does not rise to the same extent, a reduction of the size of living space is needed to make living in the future more affordable. At the same time the requirements for dwellings are becoming more diverse. Different user groups, e.g. as families, singles, shared apartments, etc. have different requirements for residential units. A spacious floor plan allows quite easily a wide range of uses. An already tight floor plan can be designed ideally for only one use, for only one designated user group. By shrinking the size of apartments therefore there is a risk that a shrunken residential unit works only for a selected user clientele. The risk of vacancy increases.

\section{Flexible dwelling concept}

In the planning and design of residential buildings therefore new solutions are needed. A greater flexibility in the use of the apartments will be required to make compact apartments interesting to the widest possible circle of potential users. By doing that, a potential vacancy can be avoided.

The average size of a standard apartment in Western Europe built in recent years can be classified approximately $75-80 \mathrm{~m}^{2}$. For the purposes of the necessity of reducing the 
flat sizes, how it is described above, it seems that a new average standard size of an apartment will be $65 \mathrm{~m}^{2}$ :

\subsection{Problem}

Apartment sizes of $65 \mathrm{~m}^{2}$ allow spacious 2-room apartments or a 3-room apartment with very narrow and small rooms. During the planning process, a decision for one of the two types is to be made. However this decision will be, in both ways it excludes the clientele that preferred the unrealized apartment type:

- A spacious 2-bedroom apartment in an exclusive location is suitable for highearning couples or a very well situated single.

- A scarcely measured, beautifully furnished 3-bedroom apartment in an exclusive location is preferably suitable for small middle-income families who need a 3rd room much, but want to live in a good neighborhood. For this clientele a bigger apartment in the same neighborhood cannot be financed, another area is not useful or wishful.

Both user groups are quite growing groups. For the client it was important to address both groups of users as potential customers in order to create an optimal basis for the best possible utilization.

The architectural office Arch-Vision from Graz developed a 'flexible dwelling concept' for a possible solution to improve flexibility in compact apartments. The aim of the concept is to optimize the living space to the needs of as many potential users. By an intelligent, customizable apartment concept a high utilization of the apartments will be reached and an impending vacancy prevented.

\section{Adaptable room solution}

To develop and implement a new adaptable room solution, conventional design steps are necessary first. Together with a private owner of an exclusive location in Graz an innovative apartment concept, developed by arch-Vision will be implemented as a prototype. The given property, $20 \mathrm{~m}$ width and $50 \mathrm{~m}$ length, is a very narrow site, an elongated basis for the proposal. In the development study, a 3-storey building with a width of $8 \mathrm{~m}$ crystallized out as a useful volume (Fig. 1).

The entrance area of the property and the connection to the public street is located north-east. So it was possible to use the Volume as a zoning of the property.

- $\quad$ On the one hand the building offers the public area for the entrance and parking in the north-east. In this case, the volume of the building cuts the public entrance-area from the rest of the property.

- On the other hand the volume defines a private garden and balcony area in the south-west, which has no visual connection to the public area. So even if the property is a very narrow property, the building concept defines public and private zones by using volumes. 


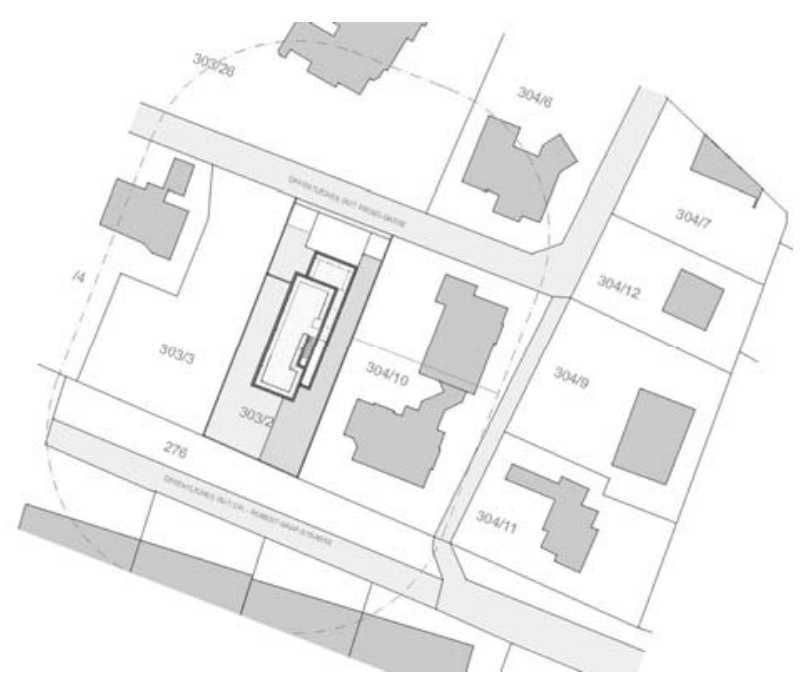

Fig. 1. Location of the given property - site plan

\subsection{Design ideas}

Those functional considerations lead to a simple architectural language. Each floor will be displayed in an easy readable volume (Fig. 2). By shifting the middle volume relative to the upper and lower volume, covered areas arise. This forms covered terraces on the west side of the building. In the north-west the protruding volume is building a covered area that can be used for parking.

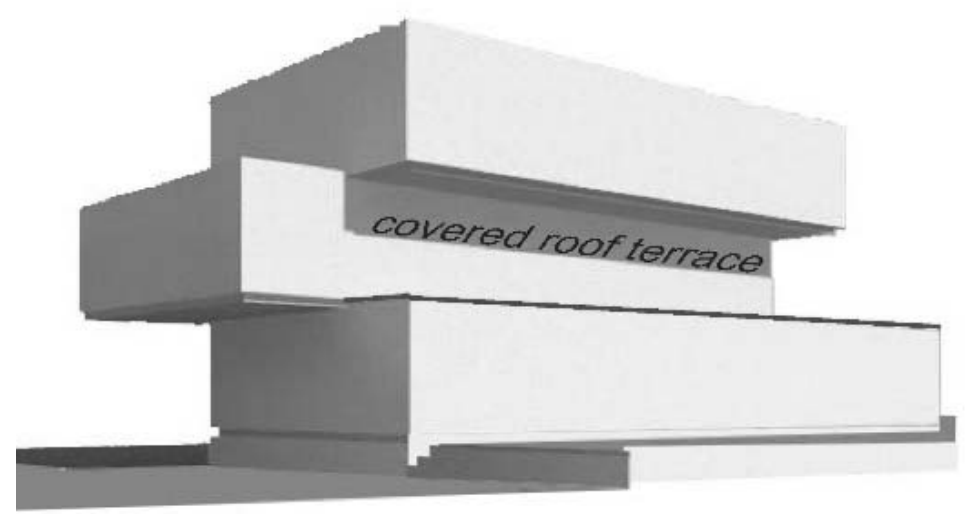

Fig. 2. Building volume - covered roof terrace

By moving the designated volumes a covered entrance area is arising at the east side. On the protruding volume spacious roof terraces for $2^{\text {nd }}$ floor are given.

Pollack Periodica 11, 2016, 1 
And although the proportion of the plot is not ideal, the building by itself is creating both: a covered entrance area and a covered car park (Fig. 3, Fig. 4), as well as an outdoor area (garden or terrace) for each apartment available.

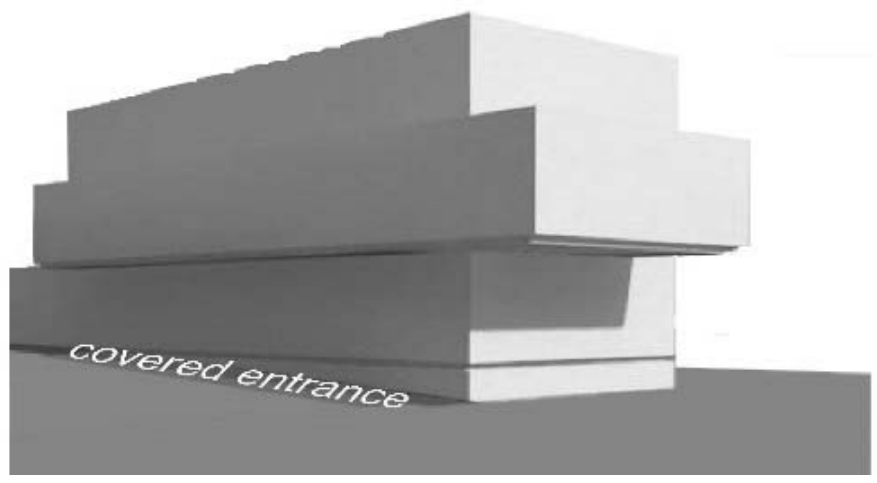

Fig. 3. Building volume - covered entrance area
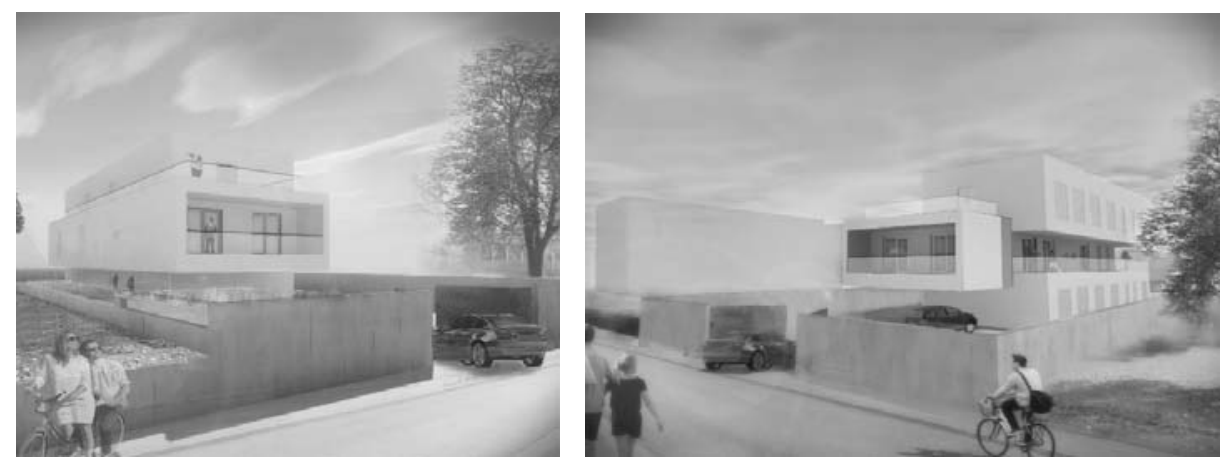

Fig. 4. Building volume - appearance to the public

\subsection{Flexible room configuration}

The real innovation is visible in the interior of the building. 6 compact apartment units are located inside of the building. Including the internal circulations and staircases the gross floor area is $400 \mathrm{sqm}$. In each of these units a FLEX zone (Fig. 5, semitransparent area in the floor planes is used. This FLEX zone is a predefined zone in which a partition wall can be moved freely without creating damages to the built environment. This allows changes of the layout of the apartment within this zone, and almost a free configuration of the unit. This offers a variety of types of use, which can respond to the most diverse requirements of potential users: 


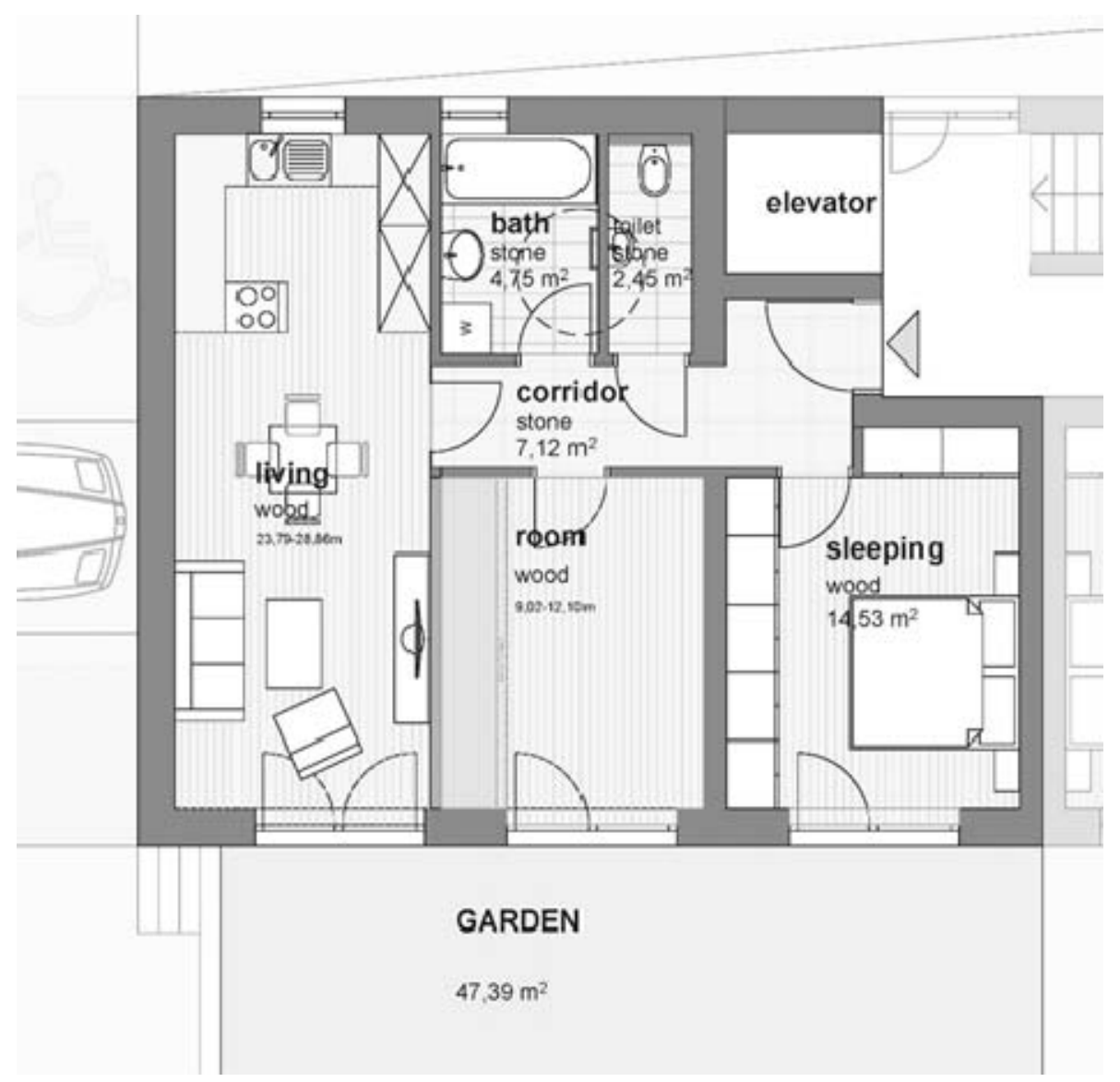

Fig. 5. Basic floor plan with FLEX zone (semitransparent area)

\subsection{Variant 1: spacious 1 bedroom apartment}

Through a complete renunciation of the partition wall a spacious 1 bedroom apartment arises. The floor is laid throughout the whole living area. Because of this, no damage of the floor or interruption of the flooring is created by giving up the partition wall.

This variant offers an apartement with high value. With this option of a spacious 1 bedroom apartment (Fig. 6), the owner can offer the apartment to potential tenants, who are singles or couples an who like to live in a generous apartment.

In this variant, the apartment is very spacious and luxury. An open living and dining area, and a spacious bedroom are significant in this variant. Bathroom and toilet are separated. By removing the partition wall between bathroom and toilet, a barrier-free design of the wet area is possible. 


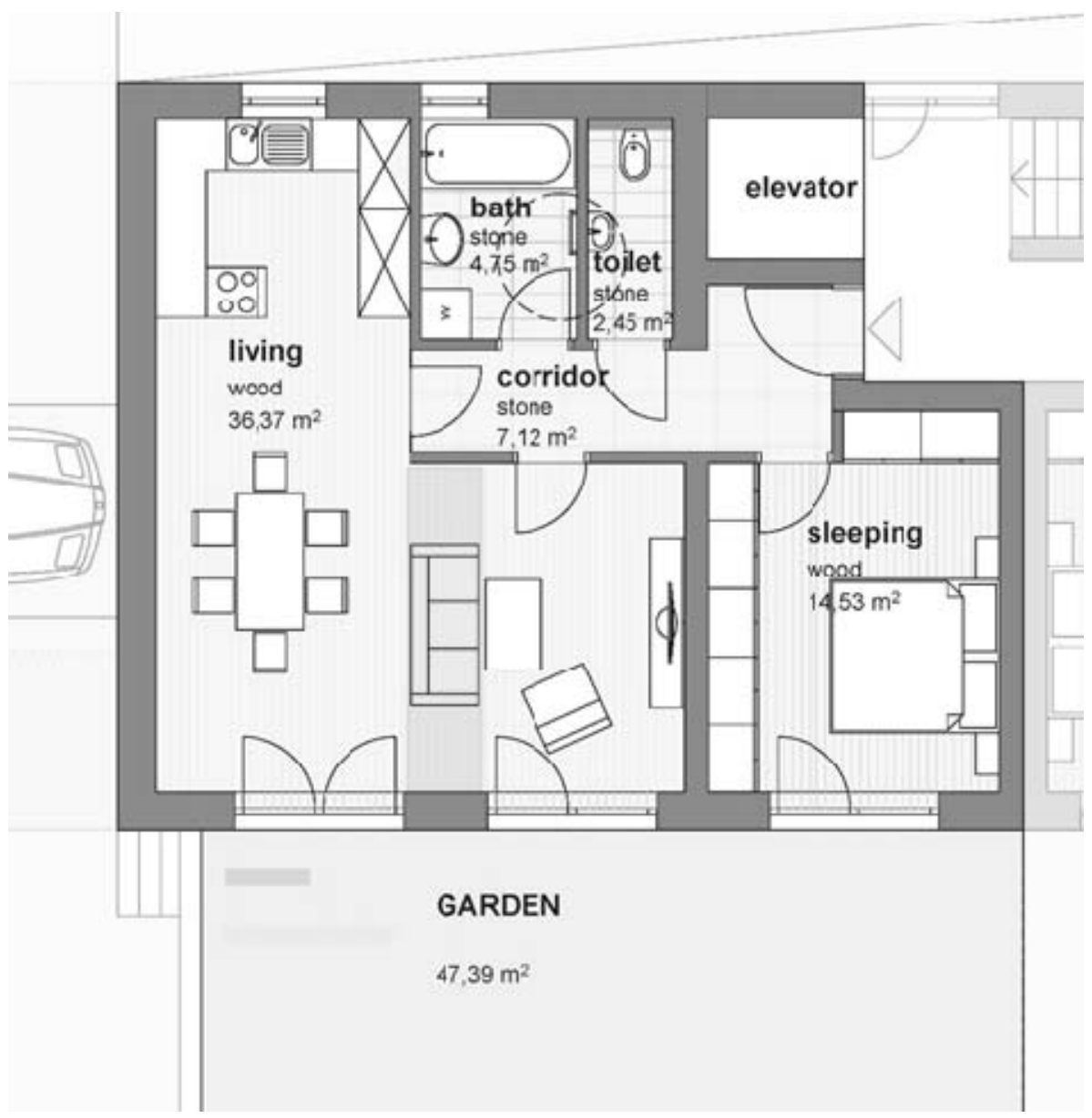

Fig. 6. Variant 1: spacious 1 bedroom apartment with open FLEX zone

\subsection{Variant 2: 2-bedroom apartment}

By using the flexible partition wall approximately in the middle of the FLEX zone (Fig. 7) the result is another full room. The wall is provided on the finished floor and acoustically decoupled by a pad from the ground. Characterized a sound transmission from the wall is prevented on the ground. Through a already scheduled door the extra space can be entered separately from the corridor.

The apartment is an open plan living and dining area, which is compact, but big enough in this variant. The spacious bedroom is unchanged. A full with $10.5 \mathrm{~m}^{2}$ space is created in addition.

In this Variant potential tenants have the possibility to creat a seperat room e.g. for a child. So for a user it is possible to rent the apartment as a 1 bedroom apartment and use 
it as a generous flat up to the user needs a second seperat bedroom. By using the FLEX wall the user can easily devide the spacious livingroom.

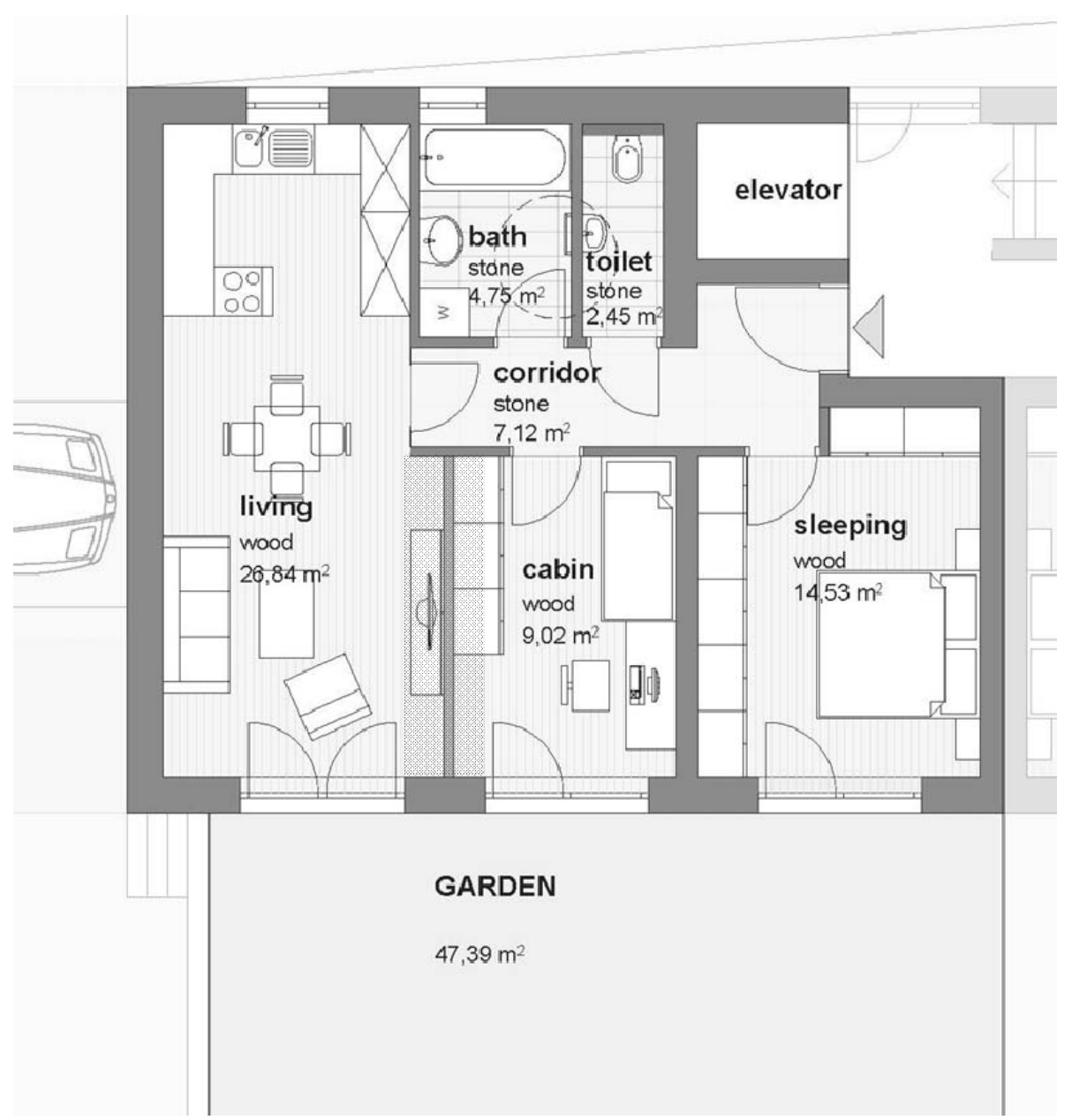

Fig. 7. Variant 2: 2-bedroom apartment with FLEX wall in the middle of the FLEX zone

\subsection{Variant 3: 1 + 1-bedroom apartment}

Depending on the users needs the living area can be temporary or permanently maximized (or even minimized) by minimizing (or even maximizing) the $3^{\text {rd }}$ room. In this variant a very narrow, compact additional room with approximately 9 sqm remains (Fig. 8). Depending on the requirements of the user, this narrow room, however, can still be a usefull space e.g. a small bedroom for a child. 


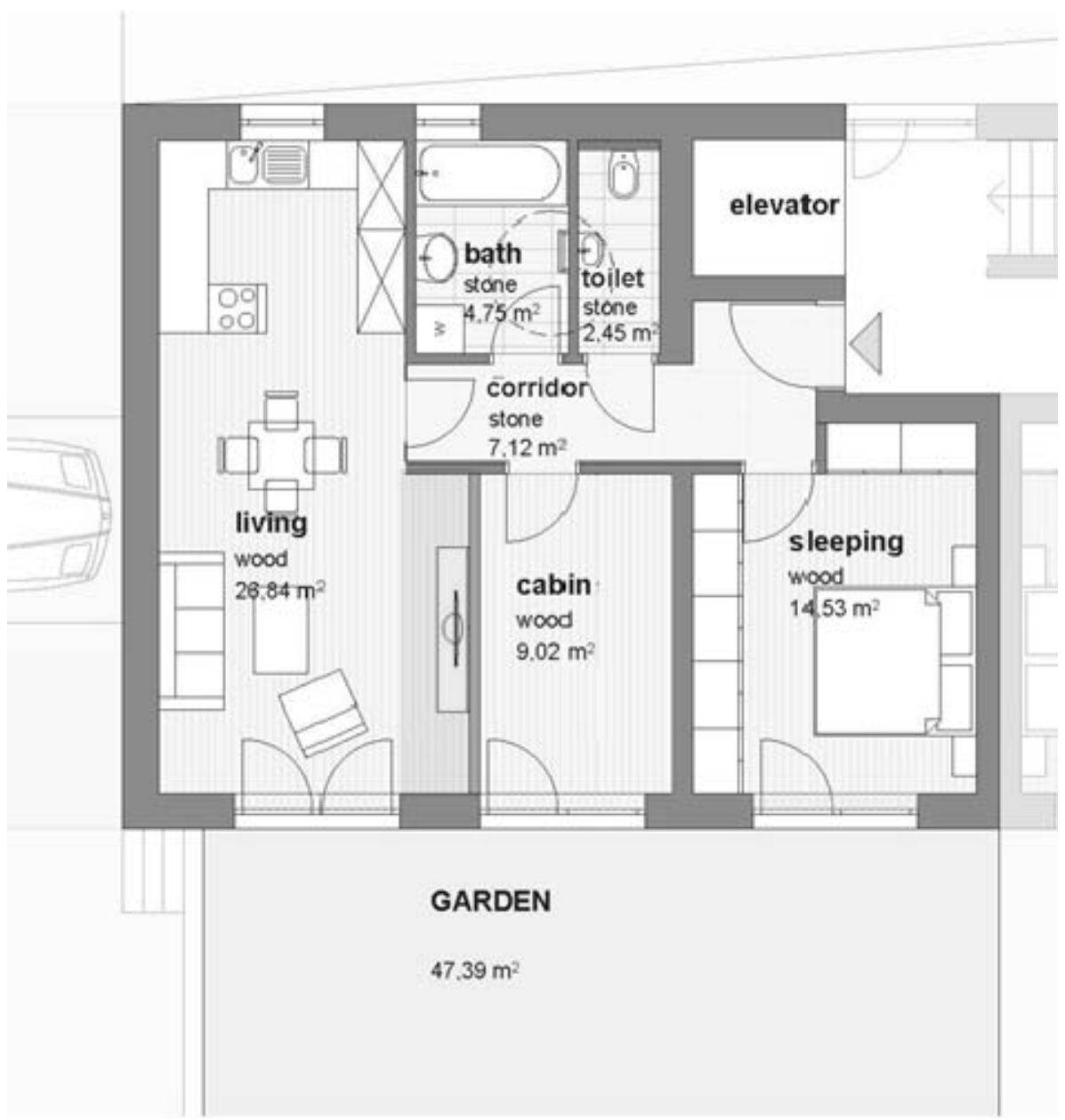

Fig. 8. Variant 3: 1+1 bedroom apartment with FLEX wall at the right side of the FLEX zone

\subsection{Variant 4: 1.5 bedroom apartment}

The flexible partition wall can also be used as a freestanding wall to separate and yet join space. So this variant offers a room configuration by the additional use of sliding doors changeable at any time.

With the FLEX wall it is possible to put an optical resolution into the generous livingroom and to create a seperated part of the spacious room.

By using sliding doors in addition to the FLEX wall, the user is able to open and to close this additional space (Fig. 9).

In this Variant the user can decide day by day, if she/he want to separate the part of the room or if she/he wants to join both parts of the room 


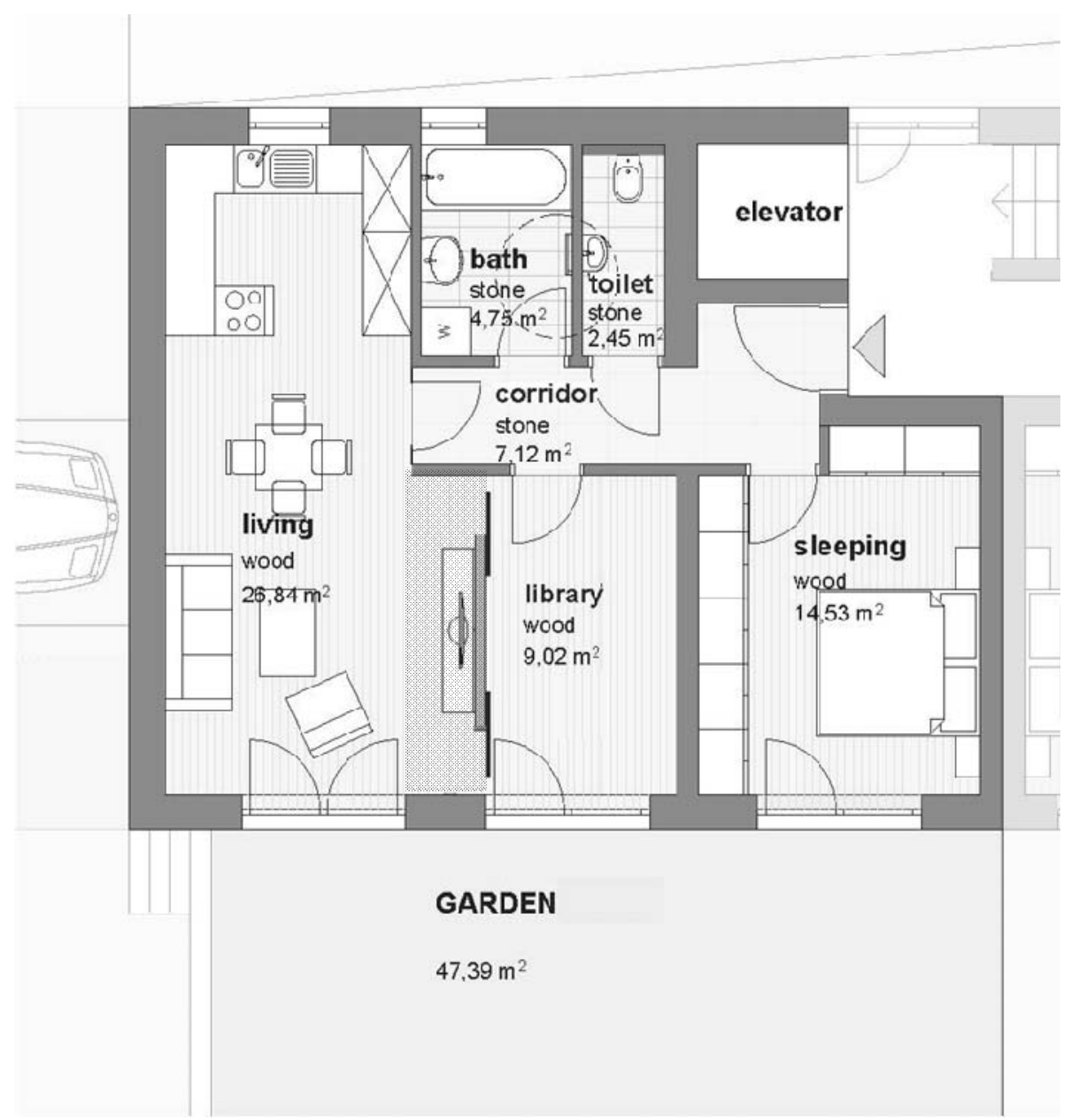

Fig. 9. Variant 4: 1.5 bedroom apartment with sliding doors and FLEX wall in the FLEX zone

\subsection{Variant 5: community living (3-bedroom apartment)}

With the addition of another partition wall that is free of damage mountable in the room on the same principles, a shared apartment for a suitable living situation can be offered. In this variant three approximately equal sized rooms can be produced, all of them are oriented to south-west and thus have an equivalent position.

So even if the variant 1-4 are adressed to singles, couples or families, this variant focusses on people who want to live in a shared apartment, e.g. a group of students (Fig. 10).

Pollack Periodica 11, 2016, 1 


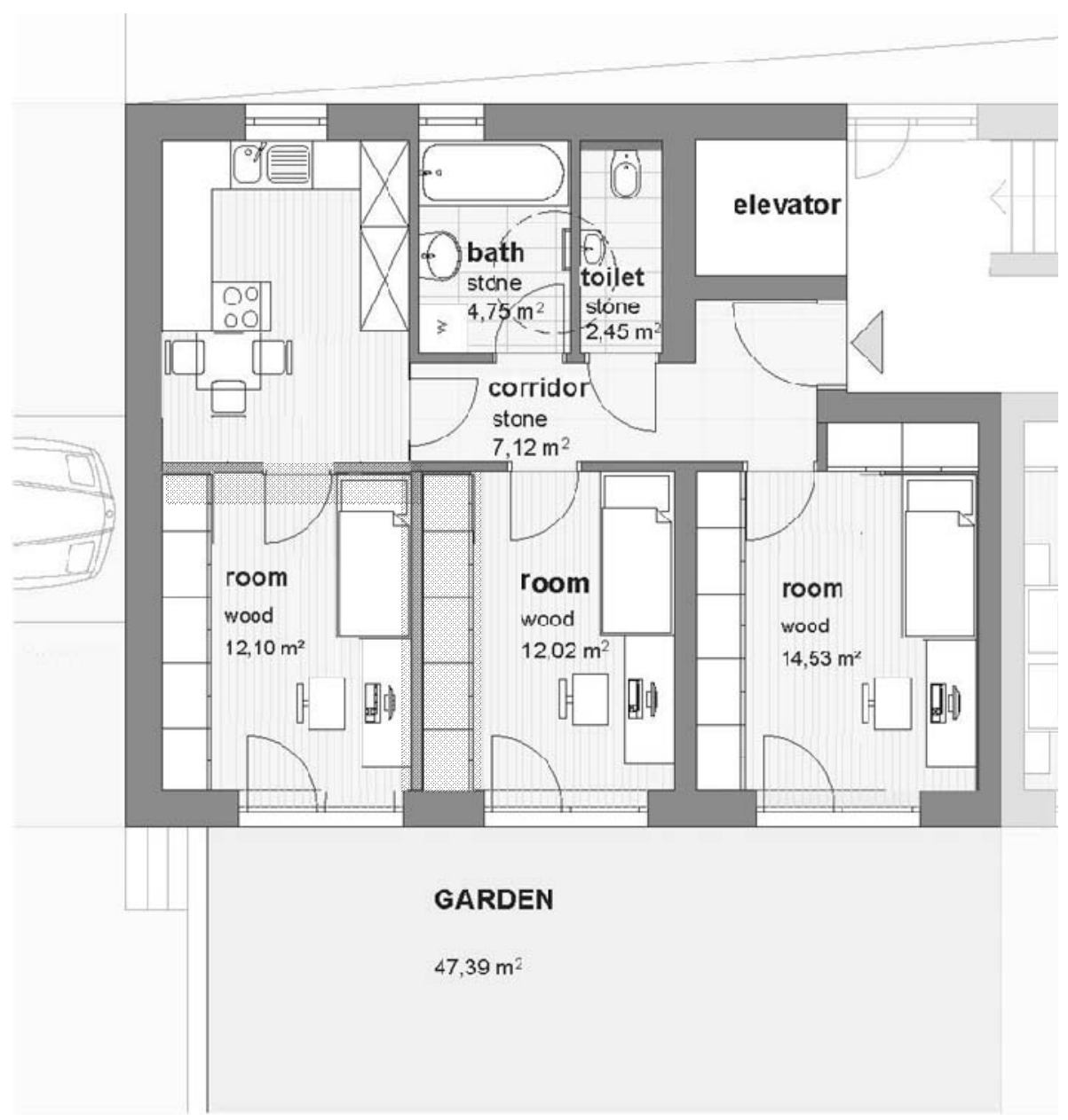

Fig. 10. Variant 5: community living with 2 FLEX walls

\section{Conclusion}

By designing a FLEX zone in combination with using a permanent flexible partition wall sytem within an apartment building creates the possibility to individualize the apartment units and configure user-specific space solutions. A big advantage is that this needs no huge reconstruction and renovation effort. Usually there is a huge expenditure by demolition of partition walls and adaptation of the interrupted floors and ceilings. Ideally, the walls can be positioned even by the user himself freely in space. Required room dimensions and dimension elements can thus also be realized during the use of the 
apartment. The result is: no significant waste, professionals have been not necessarily consulted.

With flexible space zones and permanenet flexible partition wall systems the owner of the building has permanently the ability to restore the apartment on the specific needs of the respective users. The owner can simultaneously offer a luxury 1 bedroom apartment, a reasonable 2-bedroom apartment or a shared apartment suitable for the market and make the decision for one of those varaints not until signing a lease. After that both, the owner together with the user, can decide which variant is actually needed. Neither for the user nor for the client additional financial expenses arise. Even after termination of the lease the permanently flexible use option remains. With useing such flexible partition wall systems the LifeCycleCosts of the building can be permanently reduced. The utilization rate and the recoverability of the apartments can simultaneously be permanently increased, the risk of vacancy of dwellings due to lack of prospects, or the need for conversion decreases considerably.

\section{References}

[1] Schmitz C. Die BRICs und ihre Nachfolger, Goldman \& Sachs, April 2008, http://www.boerse-frankfurt.de/DE/MediaLibrary/Document/Wissen/Urmoneit.pdf （last visited 28 June 2015).

[2] Huber T., Gatterer H., Baumgartner M., Seidl A., Varga C. Zukunft des Wohnens, Die zentralen Trends bis 2025, (Ed. Thomas Huber) Zukunftsinstitut GmbH, Klekheim, Germany, March 2013. 